\title{
Evasão escolar na educação de jovens e adultos: problematizando o fenômeno com enfoque na cultura escrita
}

\section{The Dropout in the Youth and Adult Education: Problematizing the Phenomenon with Focus in the Written Culture}

Rosângela Pedralli*

Universidade Federal de Santa Catarina

Florianópolis - Santa Catarina / Brasil

Mary Elizabeth Cerutti-Rizzatti**

Universidade Federal de Santa Catarina

Florianópolis - Santa Catarina / Brasil

RESUMO: O presente artigo é fruto de um estudo de caso de tipo etnográfico e tem como tema a evasão no universo escolar da Educação de Jovens e Adultos (EJA), em sua relação com a cultura escrita. Com o estudo, objetiva-se: (1) discutir o problema da evasão em espaços de EJA; (2) compreender em que medida a constituição identitária pode implicar no movimento de permanência/evasão no/ do espaço escolar; (3) estabelecer relações possíveis entre as práticas de letramento e esse movimento; e (4) refletir sobre a aproximação da condição de insider ou de outsider por parte dos estudantes no espaço escolar e as implicações para a evasão. O estudo defende que o fenômeno da evasão é um complexo construto social, com desdobramentos expressivos no que diz respeito aos aspectos identitários e à construção/ressignificação das práticas de letramento dos alunos, complexidade que não pode ser denegada nos processos de escolarização.

PALAVRAS-CHAVE: Educação de Jovens e Adultos; evasão escolar; práticas de letramento; constituição identitária.

ABSTRACT: This article is based on an ethnographic case study and its theme is the dropout in the youth and adult education (EJA) school environment in its relationship with the written culture. With this study, we aim to: (1) discuss the problem of dropout in EJA spaces; (2) understand the extent to which identity constitution of the study participants may involve the movement of stay/dropout in/of the school

* rosangelapedralli@hotmail.com

**ma.rizzatti@gmail.com 
space; (3) establish possible relationships between literacy practices and this movement, and (4) reflect on the access of the insider or outsider condition by students in the school spaces and its implications for school dropout. To conclude, the study argues that the phenomenon of avoidance is a complex social construct, with significant developments in relation to aspects of identity and the construction/redefinition of literacy practices of students, complexity that cannot be denied in schooling processes. KEYWORDS: Youth and adults education; dropout; literacy practices; identity constitution.

\section{Introdução}

É comum, tanto às iniciativas governamentais com foco na Educação de Jovens e Adultos (EJA), quanto aos próprios programas endereçados a essa parcela da população, a preocupação com a permanência dos educandos nas classes de diferentes níveis de escolarização (KLEIMAN, 2001a; 2001b). A evasão, nesse sentido, admitida como um fenômeno tão presente no universo escolar da EJA, especialmente, não pode prescindir de olhares que transcendam a compreensão vigente no senso comum de que faltaria interesse e comprometimento por parte dos adultos para a permanência na esfera educacional. Assim, interessa-nos discutir esse fenômeno em suas implicações no que respeita à cultura escrita, discussão que tem sido tangenciada em grande parte dos estudos no âmbito da Linguística Aplicada no Brasil.

A compreensão de que é da alçada dos alunos a responsabilidade pela sua permanência e por seu êxito na escolarização, compreensão essa flagrantemente pautada no modelo autônomo de letramento (STREET, 1984), é o que carreia o entendimento de que, sendo assim, cabe à escola, e por consequência aos seus atores sociais, empreender as ações didático-pedagógicas tal qual se desenham ao longo da história e, como componente adicional, resultante dessa realidade de evasão, proceder a um sem número de movimentos no espaço escolar que visem à "motivação" constante desses sujeitos à permanência na escola.

A nosso ver, tal fenômeno não é reflexo da incapacidade de automotivação ou da ineficiência da tentativa de motivação de outrem para a permanência do aluno no espaço escolar, tampouco é causal a falta de esforço por parte dos educandos; tendemos a crer no movimento contrário: a evasão é consequência desse processo, o reflexo de uma realidade vivida por essas pessoas nos ambientes de escolarização. Tal realidade, grosso modo, em alusão a Bourdieu (1983), tem relação com o que seria central aos alunos para a sua permanência na escola, quando do ingresso em classes escolares: a construção da identidade institucional de aluno pelos atores sociais dessa esfera em todos os níveis. 
O que menos importa, nesse sentido, é que se discuta o que efetivamente é origem e o que é decorrência de e, sim, importa que se problematizem representações cristalizadas sobre esse fenômeno nos diferentes âmbitos, ou seja, nas pesquisas de massa que tomam os sujeitos na perspectiva quantitativa quantos concluíram a escolarização, quais os índices de evasão comparativamente a esse número, quantas pessoas urge "atender" -, nas iniciativas governamentais que configuram seus programas, muitas vezes, à luz da preocupação com a manutenção dos alunos até o final do processo, nas escolas, as quais acabam tendo, em muitos casos, como preocupação subjacente às ações educativas empreendidas em sala de aula a própria manutenção desses sujeitos no espaço escolar, dentre outros exemplos que materializam tais representaçōes cristalizadas.

O que interessa a nós é a disposição de lançar luzes sobre o fenômeno da evasão escolar, discutindo os conceitos de insider e de outsider (KRAMSCH, 1998), a partir do novo olhar que o conceito ganha com a discussão proposta por Cerutti-Rizzatti, Mossmann e Irigoite (no prelo), em uma relação estreita com o conceito de práticas de letramento (STREET, 1988; HAMILTON, 2000), por compreendermos que o papel da escola, em todos os níveis, é horizontalizar (KALANTZS; COPE, 2006) a participação em eventos de letramento (STREET, 1984) e, por via de consequência, ressignificar as práticas de letramento dos sujeitos envolvidos no processo.

Para essa discussão proposta, consideramos um estudo fruto de vivência de cerca de cinco meses em uma escola da rede municipal do norte da ilha do município de Florianópolis (SC), mais pontualmente no que respeita à interação com as participantes deste estudo: três alfabetizandas ${ }^{1}$ adultas, com idade entre 43 e 52 anos, integradas no Curso de Educação de Jovens e Adultos - I Segmento da Prefeitura Municipal de Florianópolis, na respectiva classe de alfabetização de jovens e adultos e que serão identificadas, ao longo do artigo, como $E, M$ e $M G .^{2}$ Tais interaçóes contaram, ainda, com visitas pontuais à residência das participantes ao longo desse período de estudo.

\footnotetext{
${ }^{1}$ Como ficará evidente à frente, pelo conjunto de dados analisados, as participantes do estudo são assim denominadas pelo seu enquadramento formal na instituição; no entanto as três mulheres já apresentam proficiência nos usos da escrita, mesmo que em níveis diferentes.

${ }^{2}$ Estamos conscientes de que, em pesquisas com geração de dados a partir de instrumentos de tipo etnográfico, os participantes tendem a ser referenciados por nomes fictícios. Optamos, porém, por referenciar tais participantes pela inicial ou iniciais de seus próprios nomes, grafada(s) em itálico para evitar ambiguidades com o uso de letras maiúsculas.
} 
Essas três mulheres tiveram passagem pela escola na infância, tendo de deixar os estudos ainda na adolescência, movidas por questôes de natureza socioeconômica, em linhas gerais. As atividades laborais às quais se dedicam não as impelem a utilizar a escrita de modo expressivo. Do mesmo modo, a inserção dessas mulheres em outras esferas da sociedade não demanda delas usos da escrita, além dos dominados já por elas. A reinserção no espaço escolar em uma classe de alfabetização de adultos, ainda que leiam e escrevam para atender às necessidades impostas pela sua circulação social, parece ter motivações de outras naturezas e influência significativa de familiares com maior domínio da escrita (PEDRALLI, 2011).

A vivência nesse espaço com $E, M \mathrm{e} M G$ acabou por gerar um conjunto de dados composto principalmente por notas de campo - constituídas de anotaçōes manuais (OLABUÉNAGA; ISPIZUA, 1989) de interaçōes ocorridas no espaço escolar em questão e nas residências das participantes -, entrevistas semiestruturadas, realizadas nas residências dessas mulheres - gravadas em áudio (MARCONI; LAKATOS, 2007) - e imagens fotográficas. Essas entrevistas semiestruturadas foram transcritas integralmente, com ajustes de forma limitados ao critério de não exposição da face das participantes de pesquisa no que respeita aos traços variacionistas, comumente objeto de preconceito linguístico.

Importa, também, o registro de que não obedecemos a técnicas da Análise da Conversação, visto que o foco da discussão, empreendida no percurso analítico, não envolve questôes de acento e sobreposição de turnos e conceitos afins. Importa referir, ainda, que o processo de análise de conteúdo a que submetemos tais excertos se deu com base em teorizaçóes de Hamilton (2000) sobre práticas de letramento, que contemplam as categorias de participantes, artefatos, contextos e ambientes.

O critério para o recorte dos excertos, tanto das entrevistas quanto das notas de campo, foi o eixo sobre o qual se construiu a questão de pesquisa que norteia este estudo: Que implicações no âmbito da mobilidade/inserção na cultura escrita podem ser depreendidas do movimento de permanência/evasão dos sujeitos no/ do sistema escolar? Eis que segue a discussão tendo como eixo essa questão.

\section{O fenômeno da evasão na EJA: discussão preliminar objetivando o enfoque na cultura escrita}

A preocupação com o fenômeno da evasão escolar - primeiro objetivo de discussão deste estudo - perpassa, como afirmamos anteriormente, todos os níveis de ação e de participação no processo educacional - governamental, 
institucional etc. Dessa forma, constitui foco desta seção a discussão desse fenômeno à luz dos documentos que parametrizam o programa de alfabetização da rede municipal de Florianópolis, das ações da comunidade e gestores do núcleo de escolarização no qual realizamos a pesquisa, da ação docente e do relato dos alfabetizandos, especialmente das três participantes deste estudo.

Considerando, então, os documentos parametrizadores do ensino, observa-se, na Resolução n. 2/2010, que visa estabelecer as normas operacionais que instituem as Diretrizes Gerais e Operacionais para a Educação de Jovens e Adultos, uma preocupação bastante substancial com a realidade microcultural dos alunos, preocupação expressa já no artigo $1^{\circ}$ do mesmo documento, ao asseverar que constitui atribuição da EJA no município "[...] assegurar, gratuitamente, oportunidades educacionais apropriadas, consideradas as características dos estudantes, seus interesses, suas condições de vida e de trabalho [...]" (FLORIANÓPOLIS, 2010, p. 1).

Essa preocupação, pontuada pelo documento, se materializa na escola pela relação bastante próxima estabelecida entre gestão escolar, professores e alunos. $\mathrm{Na}$ comunidade escolar em questão, todos os atores diretos lancham juntos, praticam atividades conjuntamente, como jogos de futebol e ping-pong e afins. É bastante significativa a preocupação por parte da coordenação, bem como dos professores, com o absenteísmo/evasão dos alunos. Cabe registrar que, por vezes, durante o inverno chuvoso, que dificultou muito a locomoção dos alunos na época de geração de dados para este estudo, presenciei diálogos como esses - fala do coordenador pedagógico a um grupo de alunos - “(1) [...] Quando for assim [semana fria e chuvosa], vocês me liguem, que eu busco vocês. Não deixem de vir à aula, me liguem" (Diário de Campo, 8 jun. 2011, nota n. 1).

A evasão é, nos contextos de EJA, um tema recorrente entre os gestores da rede, como evidencia o projeto Nenhum a Menos. Essa questão, no projeto, é compreendida à luz da não exigência de compromisso legal quanto à participação no processo educativo dessa parcela da população, ao contrário do que acontece com crianças e adolescentes que, por lei, devem estar na escola. E elenca como causas comuns da evasão:

[...] questões objetivas da vida de nosso sujeito da EJA. São trabalhadores e trabalhadoras que, geralmente, precisam conseguir pessoas para cuidar dos filhos e parentes, lidam com ciúmes do companheiro ou companheira, muda[m] de endereço com frequência, são em sua maioria de outras cidades, mudam de emprego ou conseguem um em horário noturno, chegam aos núcleos cansados, 
com fome, são tímidos, muitos não têm pais, a família está separada, os pais não têm ensino fundamental completo, têm dificuldades de falar em público, a auto-estima é baixa, quando percebe[m] que o curso é muito diferente do que esperava[m], pensa[m] em desistir imediatamente, vivem muito próximo da violência urbana, do tráfico de drogas etc. (PMF; SME; DEC, 2008, p. 7).

Tendo isso em vista, segundo o documento referenciado neste excerto documento que traz as bases desse projeto -, todos os núcleos têm de estar preparados para atuar na prevenção do abandono do processo de escolarização. Essa prevenção deve implicar o conhecimento microcultural da comunidade escolar por parte dos professores, ou seja, “[...] é importante tentar conhecer o mais rápido possível as condições reais de vida do aluno, procurar se aproximar dele como alguém que sabe ouvir e que procura estar disponível e demonstrar que se importa com o que acontece com ele" (PMF; SME; DEC, 2008, p. 7). Nesse sentido, assim como propõe Vóvio (2010) ao refletir sobre a contribuição dos estudos do letramento, é preciso que se considere a realidade social dos sujeitos e dos contextos em que essas ações desenvolver-se-ão. A autora atenta, contudo, para a necessidade de "[...] focalização do local, para além das condições sociais e econômicas, o modo como a cultura escrita circula, é apropriada e constitui as relaçôes sociais nesses contextos" (VÓVIO, 2010, p. 108).

Nesse aspecto, parece que a preocupação dos gestores da rede, materializada nesse projeto, da gestão do núcleo de escolarização, dos docentes e dos estudiosos do tema se justifica pela alta incidência de evasão nesses espaços. Como exemplo, registramos a nota de campo que segue.

(2) Ao realizarmos nosso primeiro contato com a escola, no início do ano letivo, em março de 2011, havíamos recebido a informação de que a classe seria constituída por cerca de quinze alunos. No entanto, ao iniciarmos efetivamente as observações, em meados da segunda quinzena de abril de 2011, a turma contava com cerca de oito alunos em sala. Nunca, em todo o período de vivência na escola, houve em sala, mais do que oito alunos. Presenciamos, em vários momentos, em falas de alunos e de professores, sensibilidade em relação ao fato de determinados alunos não mais estarem participando das aulas. Tão logo se deu o início das aulas, em final de março, assim que uma professoraalfabetizadora foi lotada na escola, atendendo à solicitação do coordenador pedagógico para demanda significativa de analfabetos procurando se inserir no programa, parece ter havido um número maior de alunos, muitos dos quais logo nos primeiros encontros, desistiram do processo. Assim, ao que parece, passados os primeiros 
dias, os alunos foram abandonando o curso por razōes diversas, muitas delas não identificadas pela gestão local. (Diário de Campo, 8 set. 2011, nota n. 2).

Restavam, assim, quando da nossa inserção na turma, menos de um mês depois do início do processo, apenas alunos já com histórico de escolarização. Tais alunos remanescentes podem ser "divididos" em dois grupos: um conjunto de alunos que dava continuidade a um processo de escolarização iniciado no ano anterior, e outro grupo de alunos que já havia estudado na mesma escola em outros momentos ou era egresso do ensino regular no caso dos mais jovens.

Por vezes, observamos o coordenador e a professora responsável pela turma comentando sobre os contatos telefônicos feitos com os desistentes e os retornos obtidos. Em muitos casos, os alunos que se evadiram, após esse primeiro momento ou ao longo do primeiro semestre letivo, justificaram tal evasão por motivos de natureza laboral ou de saúde, mas sempre referiam a intenção de retornar à turma em breve, comportamento que não presenciamos acontecer.

O que parece certo é que o movimento de permanência/evasão nesses contextos tem causas diversas. Do mesmo modo, parece certo que o estabelecimento de relações de diferentes ordens no espaço escolar pode ser determinante no que diz respeito à permanência ou não nesse espaço. $\mathrm{O}$ estabelecimento dessas relações é tematizado na seção seguinte.

\section{Implicações da constituição identitária no fenômeno da evasão em EJA}

A evasão dos alunos de EJA é, como já referimos, um complexo construto social, na medida em que estão relacionadas à desistência do processo educativo questões de diferentes ordens. Pode constituir uma das nuances da evasão a ação do professor, como representante do grupo escolarizado, no sentido de conferir ou não aos sujeitos participantes das interações a identidade institucional de aluno (BOURDIEU, 1983; KLEIMAN, 2001a). Souza e Mota (2007), ancoradas no pensamento de Bourdieu (1983), afirmam que o espaço social é criado pelas vozes que nele operam, construídas pelo habitus de cada grupo social durante o processo de formação do indivíduo, ao mesmo tempo em que transcende a sua história pessoal ao ser receptor da herança cultural da sua comunidade social.

Assim, parece claro que, no movimento de evasão na EJA, está implicado um conjunto de fatores de diferentes naturezas, no qual, ao que 
tudo indica, perpassam questôes relacionadas à constituição subjetiva dos alunos - segundo objetivo da discussão proposta para o presente estudo. Isso é perceptível na importância que o estabelecimento de relações nesses espaços parece ter, como exemplifica o registro de campo a seguir: "(3) [...] Eu [participante $E$ durante a aula] gosto [de estar na escola] porque os professores são legais, brincam e conversam... Não é como nas outras escolas. As minhas amigas [colegas de escola] também são divertidas, nós nos visitamos aos domingos" (Diário de Campo, 10 maio 2011, nota n. 3).

Nas duas notas de campo que seguem, (4) e (5), remontamos as falas expressivas de questôes identitárias envolvidas nesse processo de continuidade/ evasão desses alunos de EJA. A primeira delas, uma fala do coordenador pedagógico da escola sobre retorno de alguns alunos à classe de primeiro segmento, e a segunda uma fala do aluno mencionado no relato do coordenador.

(4) Esses alunos [quatro no total] já estavam no segundo segmento, mas precisaram voltar. Já tinham feito pesquisas e tudo lá, mas tivemos que colocá-los de volta na turma de primeiro segmento. Para nós, isso é um problema porque eles pensam que estão regredindo. Nós tentamos explicar que [tal situação de retorno] é para que eles tenham mais atenção à escrita e à leitura, mas às vezes eles não entendem. Só o $L$ [aluno que não integra diretamente o grupo de participantes dessa pesquisa] que voltou porque não se deu bem na outra turma. Quando os três [colegas do ano anterior] voltaram para a alfabetização, ele ficou sozinho lá, não se enturmou, não vinha mais quase para a escola; então achamos melhor ele estar aqui no primeiro segmento. (Diário de Campo, 24 maio 2011, nota n. 4).

(5) Eu não gostava [da turma de segundo segmento], era chata. Legal mesmo era a turma do ano passado, né $E$ ? [interpela colega que voltou com ele para o primeiro segmento, por razões diferentes] A gente ria um monte, conversava, brincava, era bem legal... Agora que eles botaram nós nessa, está bom também. (Diário de Campo, 24 maio 2011, nota n. 5).

Em nosso entendimento, os relatos tomados como notas de campo remetem ao conceito de identidade, implicado no fenômeno da evasão: não se identificar com o grupo pode ser um poderoso fator em favor do abandono do processo de escolarização, sobretudo nesta fase da vida em que os alunos tendem a ser mais sensíveis à necessidade de compartilhamento identitário, dado o fato de suas representações de mundo já terem sido em boa medida consolidadas, quer sob o ponto de vista ontológico, quer sob o ponto de vista axiológico. 
Durante nossas vivências na escola, percebemos, como evidencia a discussão realizada sobre essa temática, serem constantes e comprometidos os empreendimentos da escola, bem como da gestão municipal desse processo, no sentido de tentar diminuir a evasão tão referida em documentos parametrizadores e nos trabalhos sobre EJA a exemplo daquele mencionado em seção anterior neste artigo. As ações dessa natureza, no entanto, como sinalizam dados aqui registrados, não dão conta da questão pelo grande número de fatores nela implicados. São fatores de natureza identitária, laboral, geográfica, familiar, financeira etc. Tais fatores, em alguma medida, acabam por remeter à afirmação de Stromquist (2001, p. 315) de que as necessidades de sobrevivência surgem, em determinados entornos, como parece ser o caso de grande parte dos alunos dessa comunidade escolar, "[...] com urgência muito maior e vêm muito antes de qualquer necessidade educacional”.

A evasão, assim, se configura como tema pulsante em todos os níveis de que se compõe o ensino endereçado a essa parcela da população, especialmente. Os esforços no sentido de tentar compreender os meandros do fenômeno não podem perder de vista o que move os fazeres escolares, ainda que intuitivamente: a ressignificação das práticas de uso da língua. Questão essa que, indubitavelmente, carreia o estabelecimento de relaçôes intersubjetivas, sobre o que discutiremos na seção que segue.

\section{As práticas de letramento e as possíveis interveniências no fenômeno da evasão}

As práticas de uso da escrita dos sujeitos, às quais remetem Street (2003) e Oliveira e Kleiman (2008), ao registrarem que a reconstrução crítica da história, da cultura e das práticas de letramento, ${ }^{3}$ da microcultura desses sujeitos deveria ser o ponto de partida para coconstrução de uma aprendizagem significativa, que permitiria a síntese dialética entre práticas de letramento globais e locais, parecem ser suplantadas pela urgência imposta pela questão da evasão

\footnotetext{
${ }^{3}$ Práticas de letramento, no entendimento de Street (2000; 2003), são um conjunto de comportamentos sociais profundamente associados com a identidade e a posição social dos usuários da escrita. Esse conceito tem como característica sua maior robustez quando comparado aos demais conceitos que emergem dos estudos dentro de uma abordagem social do letramento (STREET, 1988; 2000). Baynham (1995) entende as práticas de letramento como sendo formas culturalmente aceitas de se usar a leitura e a escrita, realizadas em eventos de letramento.
} 
em turmas de EJA. De fato, entendemos o movimento com base na premência que suscita: se os alunos não estiverem presentes, não há hibridização possível entre suas práticas vernaculares e as práticas de letramento da esfera escolar. Tal relação se delineia sob delicados contornos e consiste no terceiro objetivo deste estudo.

Mesmo assumindo a relação entre evasão e práticas de letramento como delicada, uma vez que a hibridização entre práticas de letramento locais e globais, processo que facultaria a ressignificação dessas mesmas práticas, depende em boa medida, mas não só, da permanência dos alunos na esfera escolar, cabe pensar essa questão por entendermos que, em alguns momentos, a escola, assumida como principal agência de letramento em determinados entornos (KLEIMAN, 2001c), peca justamente pela perspectiva que norteia historicamente o olhar dessa instituição em relação à escrita: o modelo autônomo de letramento ${ }^{4}$ (STREET, 1984).

Assumir a língua com esses contornos pode, em nossa compreensão, contribuir, em alguma medida, para a evasão, visto que o estabelecimento de relaçōes, por parte dos alunos, entre a "escrita da escola" e a "escrita extramuros da escola” pode, muitas vezes, constituir um processo demorado e difícil, já que, em linhas gerais, microculturalmente o contato com a escrita por parte desses sujeitos é restrito, cabendo à escola facultar a compreensão dessas relações, o que seguramente não é favorecido por esse modelo de letramento.

Quando a construção/ressignificação de práticas de letramento é respaldada, de modo mais sistemático, pelas relações intersubjetivas estabelecidas em outras esferas, além da escolar, os fazeres didático-pedagógicos da escola com foco na escrita parecem significar mais aos educandos, ainda que ancorados no modelo autônomo de letramento. Os dois excertos de entrevistas com as senhoras participantes deste estudo postados na sequência - (6) e (7) - parecem materializar bem a importância que o estabelecimento de relações dessa natureza - relaçôes intersubjetivas, na dimensão extraescolar, nas quais

${ }^{4} \mathrm{O}$ modelo autônomo de letramento, segundo Street (1984), é caracterizado pela (tentativa de) dissociação das dimensões social e política nas práticas de leitura e escrita. Essa dissociação entre a escrita, a leitura e os aspectos sociopolíticos solidifica falsas concepçóes, como a pseudoneutralidade do ensino, o entendimento de leitura e escrita como sistemas independentes e fechados em si mesmos e a supervalorização da escola no processo de "aquisição" de "altos níveis de letramento". Isso significa dizer, em alguma medida, que tal modelo tende a reproduzir a cultura de grupos dominantes. 
a escrita tem importante papel - pode ter para a significação das atividades propostas na escola e, também, para a permanência no espaço escolar:

(6) $[. .$.$] eu sempre estou lendo. Eu terminei um livro agora essa$ semana, eu já tô pegando outro. "O outro lado da meia-noite", de Sidney Sheldon foi que eu li, mas eu leio assim também de espíritas, da Zíbia Gasparetto, leio bastante. A minha filha comprou uma coleção muito da literatura brasileira, e eu li Madame Bovary, mas eu não gostei, mas minha filha disse: "Mãe, é questão de costume", então porque quando eu comecei a ler, foi por incentivo da minha filha, daí ela: "Oh mãe, ao invés de tu ficar olhando televisão, olhando essas coisas de novela, porque que tu não vai ler um livro que vai ter muito mais proveito? Vai ajudar assim em tudo, em todos os sentidos", daí eu comecei a ler. Pois, olha, eu peguei gosto e foi, é difícil eu não ter um livro pra ler. ( $M$, entrevista realizada em 7 ago. 2011).

(7) Eu sempre tive vontade de estudar, mas eu tive muito incentivo, assim de me incentivar mesmo, da minha filha, essa que mora comigo, a outra filha também. Porque essa aqui sempre gosta de estudar, ela está sempre... então ela "vai mãe, vai", só que tinha receio... Que nem eu te falei de matemática, de português, daí eu achei que eu ia né... Daí ela explicou que agora era diferente na EJA, que era as pesquisas, daí "então tá”, mas eu estou gostando... ( $M$, entrevista realizada em 7 ago. 2011).

O excerto (6) aponta para a centralidade que a escrita tem no cotidiano da filha e para a importância que a filha tem no movimento de construção/ ressignificação das práticas de letramento da mãe. Esse excerto sinaliza, ainda, para o fato de grande parte das interações entre ambas, mãe e filha, terem como eixo a escrita ou as relaçóes sociais que a filha estabeleceu na sua historicidade por meio da construção de práticas de letramento legitimadas pelos grupos sociais dominantes. Maciel e Lucio (2010, p. 489) afirmam que "[...] a participação nos eventos e práticas de letramento está muito mais ligada às nossas experiências sociais e culturais do que ao próprio conhecimento do saber escolarizado".

No excerto (7), a participante deste estudo focaliza o papel fundamental da filha no encorajamento acerca do seu retorno aos estudos. Além desse papel, possivelmente seja influência da filha o próprio interesse de $M$ em retomar os estudos, haja vista que a filha gosta de estudar, estando ela no momento da entrevista cursando a terceira graduação. Essas implicações da influência da filha no retorno à escolarização por parte de $M$ convergem com o que defendem Maciel e Lucio (2010) acerca das relações estabelecidas entre pessoas que dominam e utilizam autonomamente o código alfabético e adultos 
analfabetos ou em processo de alfabetização. Para as autoras, a importância da intervenção de membros familiares no processo de apropriação da leitura e da escrita não pode ser denegada.

À luz dessas considerações e retomando um postulado de Kalman (2003), a construção de determinadas práticas depende da participação dos sujeitos em múltiplas situações sociais nas quais se posicionam de tal maneira que acessam os conhecimentos e os saberes necessários para realizá-las. Tal participação, entretanto, evoca as relações intersubjetivas estabelecidas pelos sujeitos nas diferentes esferas de atividade humana (BAKHTIN, 2011), bem como a dimensão socioeconômica implicada em tal participação, já que lidar com a cultura escrita implica lidar com acessibilidades (BRITTO, 2012), aspecto discutido por Kalman (2003) quando enfatiza a distinção entre disponibilidade e acessibilidade dos/aos bens culturais que implicam a modalidade escrita da língua.

Na seção posterior, buscamos refletir sobre os meandros da participação dos sujeitos em situações sociais em que a escrita assume papel central, como é o caso da escola, e as relações possíveis entre essa participação e o fenômeno da evasão.

\section{A aproximação da condição de insider ou de outsider na esfera escolar: a relação entre as práticas de letramento e as questões identitárias à luz do fenômeno da evasão}

A participação em diferentes situações sociais traz consigo as relações estabelecidas pelos sujeitos nas diferentes esferas de atividade humana (BAKHTIN, 2011), como afirmamos anteriormente. Trata-se de relações que são múltiplas e refratadas de acordo com o horizonte apreciativo (BAKHTIN [VOLOSHINOV], 2010) de cada sujeito, horizonte que é construído no âmbito das movências e dos deslocamentos nas representaçōes desses mesmos sujeitos, o que inclui a ressignificação das práticas de letramento.

Cerutti-Rizzatti, Mossmann e Irigoite (no prelo, p. 5) discutem exatamente essa movência e esse deslocamento das representações dos sujeitos ao afirmarem que as pessoas, a exemplo do que evidenciam os dados gerados na interação com as três participantes deste estudo, quando estabelecem relaçôes com o outro cotidianamente nas diferentes esferas de atividade humana, levam consigo suas vivências, seus valores, suas representações acerca do mundo construídas até aquele momento e no "[...] 'encontro' com o outro, agentivamente incidem sobre ele e se deixam incidir pela outridade, provocando deslocamentos e movências na historicidade que carrearam até ali, no evento único e irrepetível que é cada 'encontro' em si mesmo”. 
Essas movências têm relação muito estreita com as diferentes esferas da atividade humana e, consequentemente, com a cultura escrita, o que nos remete à discussão proposta por Kramsch (1998) sobre as condições de insider e de outsider. Para a autora, derivam das relaçóes intersubjetivas que estabelecemos nessas diferentes esferas a condição de insider ou de outsider. Ser insider exige do sujeito um reconhecimento dele mesmo como membro de determinado grupo, ao mesmo tempo em que demanda dos outros esse mesmo reconhecimento. Ser outsider, por outro lado, é determinado pelo estabelecimento da condição, por parte do sujeito, de não pertencimento, de não membro do grupo; do mesmo modo, demanda que os membros do grupo em questão não legitimem esse mesmo pertencimento.

O excerto de entrevista (8) parece materializar essa participação em esferas da atividade humana na condição de outsider, na medida em que $M$ relata seu papel em um determinado grupo social, formado pela filha e por colegas de trabalho dela em situação de confraternização, como alguém que, ainda que participe de tais momentos, o faz em uma condição diferenciada em relação aos demais membros, a condição de outsider.

(8) [Sobre atividades nas horas livres, além da leitura literária, informa:] eu tenho as amigas da minha filha, lá do trabalho, que elas me adoram (risos), eu sou a mãezona, né... Daí elas vêm aqui, a gente faz almoço, sempre faz uma coisa, vai na casa de uma, da outra, quando tem um evento elas já dizem pra minha filha [me levar junto], ela diz já sei vou levar minha mala junto, que sou eu né... (risos) $(M$, entrevista em 7 ago. 2011).

Parece ser, ainda, o próprio interesse por parte de $M$ na inserção efetiva em tal grupo - composto por sujeitos com escolarização maior que a sua, dentre outros fatores -, na condição de insider, portanto, o responsável, em boa parte, pela permanência dela na escola, tanto quanto pela participação dela em eventos de letramento, na compreensão de $M$, legitimados socialmente-leitura de livros literários ou não, leitura de jornais etc. (PEDRALLI, 2011).

A relação entre essas duas condições - de insider e de outsider - não pode, entretanto, ser estabelecida em uma perspectiva dicotômica, polarizada, como advertem Cerutti-Rizzatti, Mossmann e Irigoite (no prelo, p. 7). A compreensão deve se dar "[...] à luz de um continuum, do ir-e-vir, das movências, considerando ancoragens identitárias sempre temporárias, tanto quanto movimentos de deslocamento das âncoras, na busca de novos pontos temporários de fixidez [...]" ou, como afirma Geraldi (2010), fundamentado 
no pensamento bakhtiniano, deslocamento que se dá pela busca do acabamento, da totalidade perdida inerente aos sujeitos, constantemente em processo de constituição da subjetividade. É sobre essa busca, que em boa medida motivou seu reingresso à escolarização, que $E$ discorre no excerto seguinte: "(9) Daí meu filho e minha filha me deram força, daí eu falei 'depois de vovó, eu vou estudar pra ter uma coisa pra contar pra neta depois né”" ( $E$, entrevista realizada em 12 ago. 2011).

Refletir sobre tal compreensão explicitada pelas autoras (CERUTTIRIZZATTI; MOSSMANN; IRIGOITE, no prelo), tanto quanto sobre as condições de insider e de outsider discutidas por Kramsch (1998), dessa forma, desenha-se como nodal nos processos educativos, uma vez que a noção de "ampliação da mobilidade" parece estar se estatuindo como mantra em muitos espaços escolares e em processos de formação de professores. No entendimento dessas autoras, com o qual convergimos, não cabe à escola ampliar a mobilidade dos sujeitos e, sim, facultar-lhes inserção efetiva em diferentes esferas da atividade humana, isso porque, mover-sel circular não significa necessariamente inserir-se nessas esferas, já que prescinde de "[...] compartilhamentos efetivos de vivências, de valores, de historicidades" (CERUTTI-RIZZATTI; MOSSMANN; IRIGOITE, no prelo, p. 7). Inserção, em contrapartida, implica o estabelecimento da condição de insider ou de aproximação dessa condição.

A construção ou o estabelecimento da condição de insider nas diferentes esferas da atividade humana, incluindo a escola, dependeria, como defendemos anteriormente, da compreensão do sujeito e dos outros acerca de sua condição de membro do grupo ou, como afirma Bourdieu (1983), depende, dentre outros fatores, da construção de identidade institucional do aluno. E, em boa medida, dependeria do estabelecimento dessa condição ou da aproximação dela a ressignificação das práticas de letramento dos sujeitos na esfera escolar e a permanência deles nessa esfera.

Assim, essa construção adquire importância no espaço escolar ao tentarmos compreender os inúmeros casos de evasão, especialmente no universo da EJA, embora, obviamente, não se restrinja a ela, isso porque está implicado no fenômeno da evasão, como já mencionamos, um complexo construto social, a exemplo da focalização das açôes educativas em determinados grupos sociais, do esforço do ponto de vista legal para garantir o acesso à escola para todos os cidadãos, dentre outras questóes, sobre as quais trataremos a seguir à guisa de considerações finais. 


\section{A evasão como fenômeno imbricado em um construto social complexo: algumas considerações à guisa de conclusão}

Lidar, no espaço escolar e na dimensão que transcende esse espaço - a das iniciativas governamentais -, com o fenômeno da evasão que tem configurações tão complexas do ponto de vista social e individual, ${ }^{5}$ algumas delas objeto de nossa reflexão ao longo do artigo, é certamente um desafio, desafio este que não pode ser descurado de sua relação com questôes relativas à constituição identitária dos sujeitos e à participação em espaços em que a escrita assume papel central, o que traz consigo a necessidade de refletir sobre as práticas de letramento dos sujeitos envolvidos no processo de escolarização e sobre a aproximação da condição de insider e de outsider desses mesmos sujeitos na escola.

Além dessas questôes ou, por outra, como elemento de fundo dessas questões, há o movimento, que tem sido construído ao longo da história, nos âmbitos nacional e internacional, em favor do direito de acesso à escolarização para todos os cidadãos, como mencionamos anteriormente, direito que mesmo tendo sido assegurado constitucionalmente, ainda em 1988, tem estruturado o sistema educacional brasileiro de modo a privilegiar determinados grupos (FREIRE, 1989), com a exclusão do sistema escolar, por questôes sociais de configurações mais amplas, a exemplo da discussão presente em Pedaralli (2011).

Outro mecanismo alijador é o processo de exclusão no sistema escolar pelo não domínio dos usos da escrita requeridos na/pela escola, geralmente não convergentes com os usos realizados pelos alunos de determinados entornos sociais (KLEIMAN, 2001a) ou, numa dimensão mais abrangente, pelo fato de a circulação/mobilidade pela/na esfera escolar não garantir, como discutimos anteriormente, reconhecimento, por parte dos alunos, como membros efetivos dessa esfera a ponto de não facultar "[...] um movimento de mudanças de pontos de fixidez em suas ancoragens [...]” (CERUTTI-RIZZATTI; MOSSMANN; IRIGOITE, no prelo, p. 7) ou de ressignificação das práticas de letramento, questão discutida em Pedralli (2011).

Há que se considerar, dessa forma, a evasão do sistema escolar à luz de desdobramentos de diferentes naturezas implicados no fenômeno, a fim de que as ações governamentais de fomento ao ingresso/reingresso à escola

\footnotetext{
${ }^{5}$ Individual aqui, entendido, dada nossa filiação epistemológica ao ideário históricocultural, também, como uma construção social.
} 
especialmente de jovens e adultos, os programas educacionais endereçados a essa parcela da população e as ações educativas empreendidas no espaço escolar possam efetivamente significar a esses sujeitos de modo que a escola cumpra o que é na origem o seu papel: a horizontalização das práticas de uso da língua.

\section{Referências}

BAKHTIN, M. [VOLOSHINOV, V. N]. Marxismo e filosofia da linguagem: problemas fundamentais do método sociológico na ciência da linguagem. Trad. Michel Lahud e Yara F. Vieira. 11. ed. São Paulo: Hucitec, 2010.

BAKHTIN, M. Estética da criação verbal. 3. ed. São Paulo: Martins Fontes, 2011. BAYNHAM, M. Literacy Practices: Investigating Literacy in Social Contexts. London: Longman, 1995.

BOURDIEU, P. O esboço de uma teoria da prática. In: ORTIZ, R. (Org.). Pierre Bourdieu: sociologia. São Paulo: Ática, 1983. p. 46-81.

BRITTO, L. P. L. Inquietudes e desacordos: a leitura além do óbvio. Campinas: Mercado de Letras, 2012.

CERUTTI-RIZZATTI, M. E.; MOSSMANN, S.; IRIGOITE, J. C. S. Estudos em cultura escrita e escolarização: uma proposição de simpósio entre ideários teóricos de base histórico-cultural na busca de caminhos metodológicos para pesquisas em Linguística Aplicada. No prelo.

FLORIANÓPOLIS. Conselho Municipal de Educação. Resolução n. 2 de 13 de dezembro de 2010. Estabelece Normas Operacionais Complementares em conformidade com o Parecer CNE/CEB no 06/2010, Resoluçôes CNE/CEB no 02/2010 e no 04/2010, que instituem as Diretrizes Gerais e Operacionais para a Educação de Jovens e Adultos. Disponível em: <http://www.pmf.sc.gov.br/ arquivos/arquivos/pdf/11_05_2011_12.08.55.735d2fbf7f7260f583b585211 b7bdf60.pdf>. Acesso em: 20 jul. 2013.

FREIRE, A. M. A. Analfabetismo no Brasil: da ideologia da interdição do corpo à ideologia nacionalista, ou como deixar sem ler e escrever desde as Catarinas (Paraguaçu), Filipas, Madalenas, Anas, Genebras, Apolônias e Grácias até os Severinos. São Paulo: Cortez, 1989.

GERALDI, J. W. A aula como acontecimento. São Carlos: Pedro \& João Editores, 2010 .

HAMILTON, M. Expanding the New Literacy Studies: Using Photographs to Explore Literacy as Social Practice. In: BARTON, D.; HAMILTON, M.; IVANIC, R. (Org.). Situated Literacies. London: Routledge, 2000. 
KALANTZIS, M.; COPE, B. Multiliteracies. London; New York: Routledge, 2006.

KALMAN, J. El acceso a la cultura escrita: la participación social y la apropiación de conocimientos en eventos cotidianos de lectura y escritura. Revista Mexicana de Investigación Educativa, v. VIII, n. 17, p. 37-66, ene.-abr. 2003. Disponível em: <http://www.uam.es/otros/fmee/documentos/kalman_fmee.pdf>. Acesso em: 20 jul. 2013.

KLEIMAN, A. B. (Org.). Modelos de letramento e as práticas de alfabetização na escola. In: __ Os significados do letramento: uma nova perspectiva sobre a prática da escrita. 3. ed. Campinas: Mercado de Letras, 2001c. p.15-64.

KLEIMAN, A. B. Os usos sociais da escrita e a educação inclusiva no Brasil. In: SEMINÁRIO INTERNACIONAL SOCIEDADE INCLUSIVA, 2., 2001, Belo Horizonte. Anais... Belo Horizonte: PUC Minas, 2001a. Palestras, p. 84-101. Disponível em: <http://www.proex.pucminas.br/sociedadeinclusiva/sem2/ palestras.pdf>. Acesso em: 20 jul. 2013.

KLEIMAN, A. B. Programas de educação de jovens e adultos e pesquisa acadêmica: a contribuição dos estudos do letramento. Educação e Pesquisa, São Paulo, v. 27, n. 2, p. 267-281, jul.-dez. 2001b. Disponível em: <http:// www.scielo.br/pdf/ep/v27n2/a06v27n2.pdf>. Acesso em: 20 jul. 2013.

KRAMSCH, C. Language and Culture. New York: Oxford University Press, 1998.

MACIEL, F. I. P.; LUCIO, I. S. O analfabeto e o alfabetizado: a leitura e a escrita como atividades socialmente situadas. In: MARINHO, M.; CARVALHO, G. T. (Org.). Cultura escrita e letramento. Belo Horizonte: Editora UFMG, 2010. p. 476-493.

MARCONI, M. A.; LAKATOS, E. M. Fundamentos de metodologia cientifica. 6. ed. São Paulo: Atlas, 2007.

OLABUÉNAGA, J. I. R.; ISPIZUA, M. A. La descodificación de la vida cotidiana: métodos de investigación cualitativa. Bilbao: Universidad de Deusto, 1989.

OLIVEIRA, M. S.; KLEIMAN, Angela B. Apresentação. In:

Letramentos múltiplos: agentes, práticas, representaçôes. Natal: EDUFRN, 2008. p. 7-13.

PEDRALLI, R. Usos sociais da escrita empreendidos por adultos alfabetizandos em programa educacional institucionalizado: dimensóes extraescolar e escolar. 2011. 295 p. Dissertação (Mestrado em Linguística) - Centro de Comunicação e Expressão, Universidade Federal de Santa Catarina, Florianópolis, 2011. 
PREFEITURA MUNICIPAL DE FLORIANÓPOLIS; SECRETARIA MUNICIPAL DE EDUCAÇÃO; DEPARTAMENTO DE EDUCAÇÃO CONTINUADA. Estrutura, funcionamento, fundamentação e prática na Educação de Jovens e Adultos EJA - 2008. Florianópolis: [s. n.], 2008.

SOUZA, J. F.; MOTA, K. M. S. O silêncio é de ouro e a palavra é de prata? Considerações acerca do espaço da oralidade em educação de jovens e adultos. Revista Brasileira de Educação, Rio de Janeiro, v. 12, n. 36, set.-dez. 2007, p. 505-551. Disponível em: <http://www.scielo.br/pdf/rbedu/v12n36/ a09v1236.pdf>. Acesso em: 20 jul. 2013.

STREET, B. Abordagens alternativas ao letramento e desenvolvimento. TELECONFERENCIA UNESCO BRASIL SOBRE LETRAMENTO E DIVERSIDADE, out. 2003. Paper entregue após o evento.

STREET, B. Literacy Events and Literacy Practices: Theory and Practice in the New Literacy Studies. In: MARTIN-JONES, M.; JONES, K. Multilingual Literacies: Reading and Writing Different Worlds. Philadelphia: John Benjamins B. V., 2000. p. 17-29.

STREET, B. Literacy in Theory and Practice. Cambridge (UK): Cambridge University Press, 1984.

STREET, B. Literacy Practices and Literacy Myths. In: SALJO, R. (Org.). The Written World: Studies in Literacy Thought and Action. New York: SpringerVerlag, 1988.

STROMQUIST, N. P. Convergências e divergências na conexão entre gênero e letramento: novos avanços. Educação e Pesquisa, São Paulo, v. 27, n. 2, p. 301-320, jul.-dez. 2001. Disponível em: <http://www.redalyc.org/articulo.oa?id= 29827208>. Acesso em: 20 jul. 2013.

VÓVIO, C. L. Outras perspectivas sobre a alfabetização de pessoas jovens e adultas. In: SERRANI, S. (Org.). Letramento, discurso e trabalho docente. Vinhedo: Horizonte, 2010. p. 100-115.

Recebido em 09/01/2013. Aprovado em 31/05/2013. 